\title{
Potential for Promoting Recurrent Laryngeal Nerve Regeneration by Remote Delivery of Viral Gene Therapy
}

\author{
Adam D. Rubin, MD; Norman D. Hogikyan, MD; Alex Oh; Eva L. Feldman, MD, PhD
}

\begin{abstract}
Objectives/Hypothesis: The aims of this study were to demonstrate the ability to enhance nerve regeneration by remote delivery of a viral vector to the crushed recurrent laryngeal nerve (RLN), to demonstrate the usefulness of a crushed RLN model to test the efficacy of viral gene therapy, and to discuss future potential applications of this approach.

Study Design: Animal study.

Methods: Adult Sprague-Dawley rats were assigned to two groups. In the experimental group, an adeno-associated viral (AAV) vector carrying a zinc-finger transcription factor, which stimulates endogenous insulinlike growth factor I production (AAV2-T0-6876vp16), was injected into the crushed RLN. In the control group, an AAV vector carrying the gene for green fluorescent protein was injected into the crushed RLN. Unilateral RLN paralysis was confirmed endoscopically. At 1 week, laryngeal endoscopies were repeated and recorded. Larynges were cryosectioned in $15-\mu \mathrm{m}$ sections and processed for acetylcholine histochemistry (motor endplates) followed by neurofilament immunoperoxidase (nerve fibers). Percentage nerveendplate contact (PEC) was determined and compared. Vocal fold motion was evaluated by blinded reviewers using a visual analogue scale (VAS).

Results: The difference between PEC on the crushed and uncrushed sides was statistically less in the experimental group $(0.54 \pm 0.18$ vs. $0.30 \pm 0.26, P=.0006)$. The VAS score at 1 week was significantly better in the experimental group $(P=.002)$.

Conclusions: AAV2-T0-6876vp16 demonstrated a neurotrophic effect when injected into the crushed RLN. The RLN offers a conduit for viral gene therapy to the brainstem that could be useful for the treatment of RLN injury or bulbar motor neuron disease.

Key Words: Gene therapy, viral vectors, vocal fold paralysis, reinnervation, neurologic disease, amyotrophic lateral sclerosis, adeno-associated virus, dysphonia.

Laryngoscope, 122:349-355, 2012
\end{abstract}

\section{INTRODUCTION}

Peripheral nerve injury and other neurologic processes affecting motor neurons, such as spinal cord injury and motor neuron disease, can be devastating and often fatal disorders. Our ability to treat these disorders is suboptimal, and improving therapy remains one of the biggest challenges facing medicine today.

Preservation of injured motor neurons is necessary to restore functional innervation of muscles. Depending on the nature of injury to a peripheral nerve, neuronal degeneration may occur in different ways. Degeneration of the distal axon (Wallerian degeneration) occurs with

From the Lakeshore Professional Voice Center (A.D.R.), St. Clair Shores, Michigan; and the Department of Otorhinolaryngology (A.D.R., N.D.H.) and Department of Neurology (A.O., E.L.F.), University of Michigan, Ann Arbor, Michigan, U.S.A.

Editor's Note: This Manuscript was accepted for publication October 13, 2011.

This work is the 2010 Triological Thesis of Adam D. Rubin, MD.

This work was supported by the A. Alfred Taubman Medical Research Institute, the Program for Neurology Research and Discovery, and a grant from the ALS Association. The authors have no other funding, financial relationships, or conflicts of interest to disclose.

Send correspondence to Adam D. Rubin, MD, Director, Lakeshore Professional Voice Center, Lakeshore Ear, Nose and Throat Center, 21000 E. 12 Mile Rd., Suite 111, St. Clair Shores, MI 48081

E-mail: Rubinad1968@gmail.com

DOI: 10.1002/lary.22436 axotomy. In neurodegenerative processes, "dying back" degeneration toward the cell body occurs. The cell body lasts for a longer period of time but also can die. The cell body is critical for supplying much of the metabolic milieu for axonal regeneration. ${ }^{1}$ If the cell body dies, axonal regeneration will not occur. Therefore, efforts must be made to preserve the cell soma.

An appealing strategy to protect neurons is to deliver neurotrophic growth factors to the motor neuron cell body located in the central nervous system (CNS). ${ }^{2-5}$ However, this can be challenging. These peptides do not cross the blood brain barrier and often result in deleterious side effects when delivered into the bloodstream. Delivery directly to the cerebrospinal fluid or CNS parenchyma carries risk of further injury. Furthermore, the growth factors have poor diffusion capability, which limits the effectiveness of intraparenchymal injections. ${ }^{2,3}$

The delivery of exogenous genes encoding therapeutic growth factors or activators of endogenous growth factor production is an exciting alternative to delivering the growth factors themselves. Ideally, transgene-carrying vectors could provide sustained transcription of a therapeutic gene to the specific neurons of interest. Transgene expression in vivo may be accomplished in several ways. Cell lines may be designed in vitro to constitutively express therapeutic transgenes. These cell 
lines would then be delivered directly into the parenchyma of interest ${ }^{6}$; however, the inherent risk of inducing further trauma to the compromised area must be taken into account with this approach. Alternatively, neurotrophic viral vectors carrying the desired transgenes can be constructed. Such viral vectors can be injected into the peripheral nervous system or adjacent tissue for selective transport into the CNS via retrograde axonal transport. ${ }^{2,3,7-11}$ This technique avoids the potential trauma of direct injection by instead delivering the vector remotely to more surgically accessible nerves or muscles. It also adds the potential advantage of cell selectivity, as one can target specific motor neurons by injecting into the appropriate target muscle or peripheral nerve.

Herpes simplex virus, retroviruses, adenovirus, and adeno-associated virus $(\mathrm{AAV})^{2-4,7-10,12}$ have all been applied in vivo for gene transfer to the nervous system. Viruses are attenuated using standard techniques for gene insertion and deletion. Local proliferation is prevented by removing necessary parts of the viral genome, and potentially therapeutic genes are inserted. Adenoviruses have been the predominant vectors used for gene therapy to the nervous system, but they do have recognized disadvantages. The primary disadvantage is limited duration of gene expression. Other vector delivery systems have been developed to prolong gene expression including "gutted" adenovirus (from which potentially immunogenic genes are deleted), lentiviruses, and $\mathrm{AAV}^{2,3}$

The purpose of this study was severalfold: first, to demonstrate the ability to enhance nerve regeneration by remote delivery of a viral vector to the crushed recurrent laryngeal nerve ( $R L N)$; second, to demonstrate the usefulness of a crushed RLN model to test the efficacy of viral gene therapy; and third, to discuss future potential applications of this approach.

\section{MATERIALS AND METHODS}

\section{Rat Surgeries}

Ten adult Sprague-Dawley rats were assigned randomly to two groups of five. Rats were anesthetized with intraperitoneal ketamine $(77 \mathrm{mg} / \mathrm{mL})$ and xylazine $(4.62 \mathrm{mg} / \mathrm{mL})$ for induction. Preoperative vocal fold mobility was confirmed by laryngeal endoscopy. Anesthesia was maintained with isoflurane $(0.8 \%$ to $1.5 \%$ ) delivered by a nose cone. A vertical cervical incision was made, followed by division of the platysma and strap musculature. Using a dissecting microscope (Stereozoom 6; Leica, Buffalo, NY), the right RLN was exposed and dissected circumferentially from the midtrachea to the inferior margin of the right thyroid lobe. The nerve was then crushed with a jeweler's forceps at the level of the sixth tracheal ring for 30 seconds. Each nerve was crushed by the same investigator. The investigator was not aware of which viral vector the rat would receive. Viral injection was then performed (described later), and the wound was closed in a multilayer fashion. All experiments conducted in the present study were reviewed and approved by the University of Michigan Committee on Use and Care of Animals and the University of Michigan Biological Research Review Committee before initiation.

\section{Laryngeal Endoscopy}

Laryngeal endoscopy was performed after each crush procedure to confirm unilateral vocal fold paralysis. Endoscopic examinations were recorded onto a digital recording device (Stryker endoscopic tower, 30-degree endoscope; Stryker Endoscopy, San Jose, CA). Vocal fold motion was recorded while the rats breathed spontaneously. Endoscopy was also performed after induction anesthesia before sacrifice at 1 week.

\section{Viral Injections}

The right RLN of rats in the experimental group was injected with $5 \mu \mathrm{L}$ of AAV2-TO-6876vp16 (insulinlike growth factor [IGF] activator) 6.55e8 vg/mL (Lot \# 05-120B; Applied Viromics, Freemont, CA) (Sangamo Biosciences; Richmond, CA) using $70 \mathrm{~nL}$ boluses (5\% volume error). This is an AAV vector carrying the transgene for an IGF-I transcription factor. The advantage of employing the engineered zinc finger transcription protein for production of IGF-I is that it allows for the endogenous production of all IGF-I isoforms, not just specific isoforms, as would occur with the other more standard approaches. A concentration of $6.55 \times 10^{8} \mathrm{vg} / \mathrm{mL}$ was used. The right RLN of rats in the control group was injected with AAV2CMVeGFP. This is an AAV vector carrying the transgene for green fluorescent protein (GFP). A concentration of $4.41 \times 10^{12} \mathrm{vg} / \mathrm{mL}$ was used.

A glass micropipette puller (PP-83; Narishige, Tokyo, Japan) was used to taper micropipette tips to a $50-\mu \mathrm{m}$ size. Micropipettes were advanced beneath the perineurium along the nerve using an oocyte microinjector and micromanipulator (Nanoject; Drummond, Broomall, PA). Gentle counter traction was placed on the nerve during viral injection, using a 5-0 polypropylene suture.

\section{Sacrifice}

Prior to euthanasia at 1 week, rats were anesthetized and endoscopy was performed. Endoscopic data were recorded on a digital recorder. Intracardiac perfusion $(98.75 \mathrm{~mL}$ of $1 \times$ phosphate buffer $[\mathrm{PB}]$ solution and 1,250 units of heparin) was performed. The larynx was removed and placed into 2-methyl butane surrounded by a bath of liquid nitrogen for 5 seconds and was then wrapped in aluminum foil and placed into the $-80^{\circ} \mathrm{C}$ freezer. Specimens were moved to the $-20^{\circ} \mathrm{C}$ freezer before sectioning.

\section{Acetylcholinesterase and Neurofilament Immunohistochemistry}

Cryosections $(20 \mu \mathrm{m})$ were processed for acetylcholine histochemistry (motor endplates) followed by neurofilament immunohistochemistry (nerve fibers). The sections were hydrated in water and placed in sodium sulfate $(20 \%$ solution in water) for 5 minutes. The sections were rinsed in water followed by incubation in acetylcholinesterase solution (5-bromoindoxyl acetate, $4.0 \mathrm{mg}$; ethanol, $0.3 \mathrm{~mL}$; potassium ferrocyanide, $63.0 \mathrm{mg}$; potassium ferricyanide, $50.0 \mathrm{mg}$; Tris hydrochloric acid, $42.0 \mathrm{mg}$; Tris base, $4.0 \mathrm{mg}$; calcium chloride, $33.0 \mathrm{mg}$; and deionized water, $30.0 \mathrm{~mL}$ ) and incubated for up to 1.5 hours at $37^{\circ} \mathrm{C}$ until bright blue endplates could be clearly distinguished.

Following the acetylcholinesterase staining, the sections were rinsed in PB (11.9 mM phosphates, $137 \mathrm{mM}$ sodium chloride, and $2.7 \mathrm{mM}$ potassium chloride). The sections were placed in hydrogen peroxide ( $0.5 \%$ in $\mathrm{PB})$ for 10 minutes to quench endogenous peroxidase activity followed by two 10-minute rinses in $\mathrm{PB}$. The sections were blocked in $\mathrm{PB}$ containing $0.1 \%$ Triton-X (Sigma, St. Louis, MO) 100, $2 \%$ nonfat dry milk, and $1 \%$ normal serum to reduce nonspecific adherence of antibody. Primary antibody (polyclonal, neurofilament, 1:1,000, Cat\# AB1981; Chemicon International Inc., Temecula, CA) was applied, and the sections were incubated over night at 


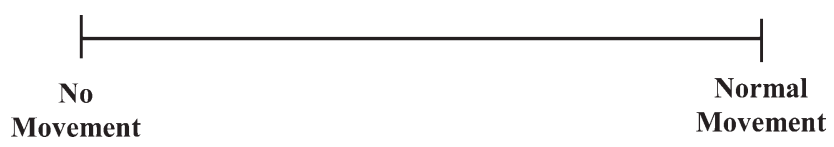

Fig. 1. Visual analogue scale used for blinded evaluation of recorded rat endoscopies. Scores were measured as distance from normal movement end.

room temperature. Following primary antibody, sections were incubated with secondary antibody (anti-rabbit IgG biotinylated, Vectastain ABC kit, Cat\# PK4001; Vector Laboratories, Inc., Burlingame, $\mathrm{CA}$ ) and developed with Vectastain $\mathrm{ABC}$ and DAB (Peroxidase substrate kit; Vector Laboratories, Inc.). The sections were rinsed with $\mathrm{PB}$ and dehydrated through ethanol (50\% for 2 minutes, $70 \%$ for 2 minutes, $95 \%$ for 2 minutes [twice], $100 \%$ for 2 minutes [twice], and xylene for 10 minutes [twice]) and mounted with DPX (Electron Microscopy Sciences, Hatfield, PA).

\section{Data Analysis}

Percentage nerve-endplate contact. Percentage nerveendplate contact (PEC) was determined by manually counting the total number of endplates making contact with neurofilament and dividing by the total number of endplates present in each section under light microscopy $(40 \times)$. This was performed by a single blinded investigator not involved in the histologic preparation of the slides. Approximately every seventh section was evaluated. PEC was recorded as a fraction of 1 (for example, $80 \%$ is recorded as 0.80 ).

Endoscopy data. Endoscopic examinations were randomized and placed on CD-ROMs, which were sent to two fellowship-trained laryngologists unaware of the purpose of the experiment. The reviewers were provided a visual analogue scale (VAS) (Fig. 1) and asked to evaluate right-sided vocal fold motion in relation to the left vocal fold. The reviewers scored examinations from day 0 of the control group and from day 7 of the control and experimental groups. The reviewers' scores were quantified by measuring the distance between the scores and the "normal" end of the VAS. Of note, the digital recorder failed to record the endoscopic examinations from day 0 in the experimental group; therefore, these data were not evaluated by the blinded reviewers. However, vocal fold paralysis had been confirmed in all the members of this group after nerve crush. Furthermore, the day 0 data were not important in the statistical analysis.

Statistical analysis. Data were entered into an excel spreadsheet and cleaned. Standard $t$ tests were used to compare groups. $P<.05$ was considered statistically significant.

\section{RESULTS}

PEC was measured for the crushed (right) and uncrushed (left) side in each group. The left side was used as an internal control for each group. The difference between PEC on the crushed and uncrushed sides was statistically less in the experimental group (0.54 \pm 0.18 vs. $0.30 \pm 0.26, P=.0006)$, suggesting faster reinnervation or less denervation in the group treated with the viral vector carrying the IGF-I activator gene (Table I).

At day 0 (immediately after crush), the mean VAS score for right vocal fold movement was $99 \pm 1.5 \mathrm{~mm}$. At day 7, the mean VAS scores were $40 \pm 33.2 \mathrm{~mm}$ in the control group and $5.6 \pm 6.7 \mathrm{~mm}$ in the experimental group. A lower VAS score reflects greater vocal fold mobility. A score of 0 suggests normal mobility, and a score of $100 \mathrm{~mm}$ indicates no movement (paralysis). The difference in VAS scores at day 7 between the experimental and control group is statistically significant $(P=$ .002) (Table II).

\section{DISCUSSION}

Nerve cells, unlike other cells in the body, do not divide or replicate; once neurons are lost, the body cannot replace them. Therefore, preventing neuronal loss is critical after nerve injury or disease to have the best chance of functional recovery. To date, most of the research in neuronal protection has been focused on preservation or protection of cell bodies within the spinal cord. Approaches fall into four main categories: delivering neurotrophic factors, delivering stem cells, blocking endogenous growth-inhibiting signals, and inhibiting the inflammatory response after injury. ${ }^{13}$ In clinical practice, the only accepted approach to date for preventing permanent nerve injury is providing high-dose steroids. If high-dose methylprednisolone is given within 8 hours of spinal cord injury, patients are more likely to have improved motor and sensory outcomes. ${ }^{14}$ Steroids also are used for cranial nerve injuries. They are recommended for the treatment of acute facial nerve paralysis ${ }^{15}$ and frequently are used in the treatment of sudden sensorineural hearing loss. ${ }^{16}$ Treatment of motor nerve injury remains suboptimal, however, and efforts must continue to find better methods of neuronal preservation and repair. ${ }^{17,18}$

Efforts to develop more effective approaches to promoting neuronal survival and function following injury have focused on neurotrophic factors. Most of these neurotrophic factors are produced by glial cells within the central and peripheral nervous system, including IGFI, ${ }^{4,5,19-22}$ brain-derived neurotrophic factor, ${ }^{23}$ neurotrophin-3, ${ }^{24}$ nerve growth factor, ${ }^{25}$ and glial cell-derived

\section{TABLE I.}

Difference Between Percentage Nerve Endplate Contact in Crushed Versus Uncrushed Sides in Rats Injected With Insulinlike Growth Factor-I Activator Gene and Those Injected With Control.

\begin{tabular}{lccc}
\hline & $\begin{array}{c}\text { PEC Left Side } \\
\text { (Internal Control) }\end{array}$ & $\begin{array}{c}\text { PEC Right } \\
\text { Side }\end{array}$ & $\begin{array}{c}\text { Difference Between } \\
\text { Left and Right Sides }\end{array}$ \\
\hline Experimental group (injected with activator gene vector) & $0.84 \pm 0.10$ & $0.54 \pm 0.23$ & $0.30 \pm 0.26$ \\
Control group (injected with empty vector) & $0.74 \pm 0.10$ & $0.20 \pm 0.16$ & $0.54 \pm 0.18$ \\
\hline \hline
\end{tabular}

The difference is smaller in the group injected with the activator gene, demonstrating enhanced regeneration or less degeneration $(P<.0006, t$ test). $\mathrm{PEC}=$ percentage nerve-endplate contact. 
TABLE II.

Visual Analogue Scale Results.

\begin{tabular}{lccc}
\hline & Day 0 & $\begin{array}{c}\text { Day 7 } \\
\text { Experimental }\end{array}$ & $\begin{array}{c}\text { Day 7 } \\
\text { Control }\end{array}$ \\
\hline $\begin{array}{l}\text { Millimeters from } \\
\text { normal motion }\end{array}$ & $98.5 \pm 1.6$ & $5.3 \pm 6.7$ & $39.8 \pm 33.2$ \\
\hline \hline
\end{tabular}

Millimeters from normal motion as recorded on a visual analogue scale by two blinded reviewers when asked to evaluate endoscopic recordings of rat vocal fold motion within each group at day 7 and day 0 . A larger number signifies less vocal fold motion (maximum, $100 \mathrm{~mm}$ ). The closer the number is to 0 , the greater the vocal fold motion. Rats that received the insulinlike growth factor-I activator gene had significantly greater gross vocal fold motion at day $7(P<.002, t$ test $)$.

neurotrophic factor. $^{26}$ Although vascular endothelialderived growth factor was discovered as a factor that stimulates endothelial cell division and migration, leading to new blood vessel formation, both in vivo and in vitro studies have demonstrated it also has neurotrophic properties. $^{27,28}$

IGF-I has a number of characteristics that make it a particularly attractive therapeutic candidate. Not only does it enhance neuronal survival, it stimulates neurite outgrowth, myelination, and neuronal migration. It acts in both the central and peripheral nervous systems and is the only growth factor involved in both sensory and motor nerve regeneration. ${ }^{4,5,21,22}$ Potentially, it should be useful in the treatment of a number of pathologic processes, including peripheral nerve injury, spinal cord injuries, demyelinating disease, and degenerative neuromuscular diseases.

Multiple models of peripheral nerve injury have demonstrated improved regeneration after treatment with IGF-I. ${ }^{21,22,29,30}$ Rat models have demonstrated that endogenous IGF-I and IGF-I receptor are upregulated after sciatic nerve injury, suggesting an endogenous response to an attempt to stimulate neurite outgrowth. ${ }^{21,31,32}$ In diabetic rat models, however, this upregulation is impaired. Furthermore, reduced serum levels of IGF-I and IGF-I receptor have been demonstrated in human patients with diabetic neuropathy, suggesting this may play a role in the pathophysiology of the disease. ${ }^{21,33}$ Shiotani et al. ${ }^{34}$ demonstrated that IGF-I had neurotrophic effects when delivered to the rat thyroarytenoid muscle after RLN transection. Rats that received a nonviral muscle-specific vector carrying the gene for IGF-I demonstrated increased muscle fiber diameter, shorter motor endplate length, and an increased PEC 28 days after RLN transection. ${ }^{3,34}$

Viral vectors remain an attractive approach for therapeutic transgene delivery to injured motor neurons. $\mathrm{AAV}$ vectors have become frequently used vehicles for gene therapy. Advantages to AAV compared to traditional adenoviral vectors include the following: duration of transcription, with some studies reporting persistence for years; lack of pathogenicity of the wild-type virus; less immunogenicity; and numerous available serotypes. Although wild-type AAV has been reported to integrate into chromosome 19q13.4, establishing latency, currently available $\mathrm{AAV}$ vectors are not able to integrate into host DNA. $^{35}$
Rather than express a therapeutic growth factor, the vector used in this study carried a gene for a zinc finger protein (ZFP) transcription factor (TF). ZFP-TFs are activator genes that stimulate endogenous production of growth factors. ZFPs recognize and bind to specific DNA sequences. They are the largest class of DNA-binding domains found in human transcription factors $^{36}$ and can be paired with either activator or repression domains. For example, the VP16 domain from herpes simplex virus and p65 domain from the NF- $\kappa \mathrm{B}$ transcription factor are used to create activator TFs. These TFs can bind a DNA sequence within a promotor to drive endogenous expression of a gene or in vitro expression of a transgene. ${ }^{36}$ ZFP-TFs have been shown to increase protein production in mammalian cells. ${ }^{37}$ Snowden et al. used ZFP-TF to repress vascular endothelial growth factor-A in human cancer cell lines. ZFPTFs have been designed to increase endogenous production of the human erythropoietin gene ${ }^{39}$ and vascular endothelial growth factor. ${ }^{40}$ An advantage of using ZFPTFs as opposed to exogenous therapeutic transgenes is the endogenous production of all splice variants of a growth factor in the correct proportions. Appropriately proportioned expression of all splice variants is important for cellular regulation. ${ }^{41,42}$

Peripheral injection of viral vectors into surgically accessible nerve or muscle is the least invasive way to deliver viral vectors to the CNS. It also offers motor neuron selectivity by delivering to specific motor neurons. The sciatic nerve has been used to deliver vectors to the spinal cord. ${ }^{11,43}$ A crushed sciatic nerve model has been used extensively to investigate remote delivery of viral vectors to the spinal cord. Studies have demonstrated that peripheral injection into nerve results in greater CNS gene expression than delivery into muscle. ${ }^{11}$ Intraneural colchicine inhibits delivery of peripherally injected vectors to the CNS, suggesting that the vectors are delivered by retrograde axonal transport. ${ }^{44}$ Furthermore, modifications of viral vectors using small peptides such as Tet-1 may enhance retrograde axonal transport, resulting in quicker, more efficient delivery to the CNS, and enhance cell selectivity. ${ }^{44}$

To target the brainstem, cranial nerves must be used. We have demonstrated that both adenoviral and $\mathrm{AAV}$ vectors can be delivered to the rat brainstem via peripheral injection into the crushed rat RLN. ${ }^{2,3}$ Using an AAV vector carrying the gene for GFP, we reported expression for as long as 3 weeks. Similar to findings in sciatic nerve experiments, expression of the transgene is seen extensively in the target nucleus (nucleus ambiguus) but also beyond the nucleus and on the contralateral side, suggesting transsynaptic delivery of the virus within the CNS. ${ }^{2,3,11,43}$ Via fluorescent in situ hybridization we demonstrated that the virus itself, and not just the expressed transgene product, is delivered to the neurons in the nucleus ambiguus. ${ }^{2,3}$

The crush model of RLN injury used in the current study was developed to test the efficacy of viral vectors delivered to the brainstem to enhance neuronal regeneration. Similar to work by Shiotani et al. ${ }^{34}$ to assess injury after RLN transection in the rat, PEC is 
evaluated. Modifications were made to streamline the tissue processing. The immunohistochemical technique used in this study was developed to replace the silver impregnation technique of Pestronk and Drachman. ${ }^{45}$ Silver easily precipitates and often involves tedious care of all glassware. The techniques used in the current study to stain neurofilaments and motor endplates are just as effective for tissue evaluation and easier to perform (Fig. 2).

The natural time course of injury to regeneration after crush injury to the RLN suggests a window of opportunity for detecting a positive effect of viral gene therapy. Crush yields a Sunderland type 2 injury, and normally full recovery is expected after a few weeks. At 1 week after RLN crush, PEC drops to $20 \%$. By 2 weeks after crush, PEC increases to 54\%, and full recovery ( $80 \%$ PEC) is seen at 3 weeks. These data suggest that the optimal time to observe an effect of a viral vector would be at the 1 week time point. ${ }^{46}$ AAV2-TO-6876vp16 used in the current experiment accelerated regeneration or limited degeneration so that more than 50\% PEC was observed at 1 week (Table I) (Fig. 2). Furthermore, the blinded endoscopic evaluations strongly demonstrated earlier functional return in the rat groups treated with remote injection of the viral vector (Table II).

We have also demonstrated in previous work that injection of virus into the RLN creates no significant additional injury when performed after crush. ${ }^{2}$ Neuronal death may occur after adenovirus is directly injected into CNS parenchyma. Injury may be due to mechanical insult from the injection, host immune response, neuronal transduction by a large number of viral particles, or toxicity of the viral capsid. All of the above mechanisms require exposure of the cell body or surrounding antigen presenting cells to viral capsids. Direct exposure to capsids is reduced by injecting peripherally. ${ }^{2,3,43,11}$

The purpose of a nerve crush model is not to investigate how to enhance regeneration after a crush injury in clinical practice. Crush injuries typically recover fully without any intervention. Rather, the purpose is to provide an instrument to test the efficacy of potentially useful viral vectors. The crush model offers several advantages, including being able to observe an effect in a short period of time. This can reduce significant study expenses, such as animal housing and care.

In terms of RLN injuries in clinical practice, perhaps the most pressing issue is how to restore vocal fold motion after RLN transection. Although a neurorrhaphy can be performed, this seldom results in restored vocal fold function. Even if neuronal regeneration could be enhanced after neurorrhaphy, this would likely not restore vocal fold motion due to synkinesis-nonspecific reinnervation of abductor and adductor muscles. Current treatment techniques for unilateral vocal fold paralysis, including injection laryngoplasty, type-I thyroplasty, arytenoid adduction, and reinnervation, provide only a geometric solution by medializing or preventing atrophy of the paralyzed vocal fold to improve glottic closure.

Reinnervation procedures have been described to try to avoid synkinesis, primarily by trying to promote
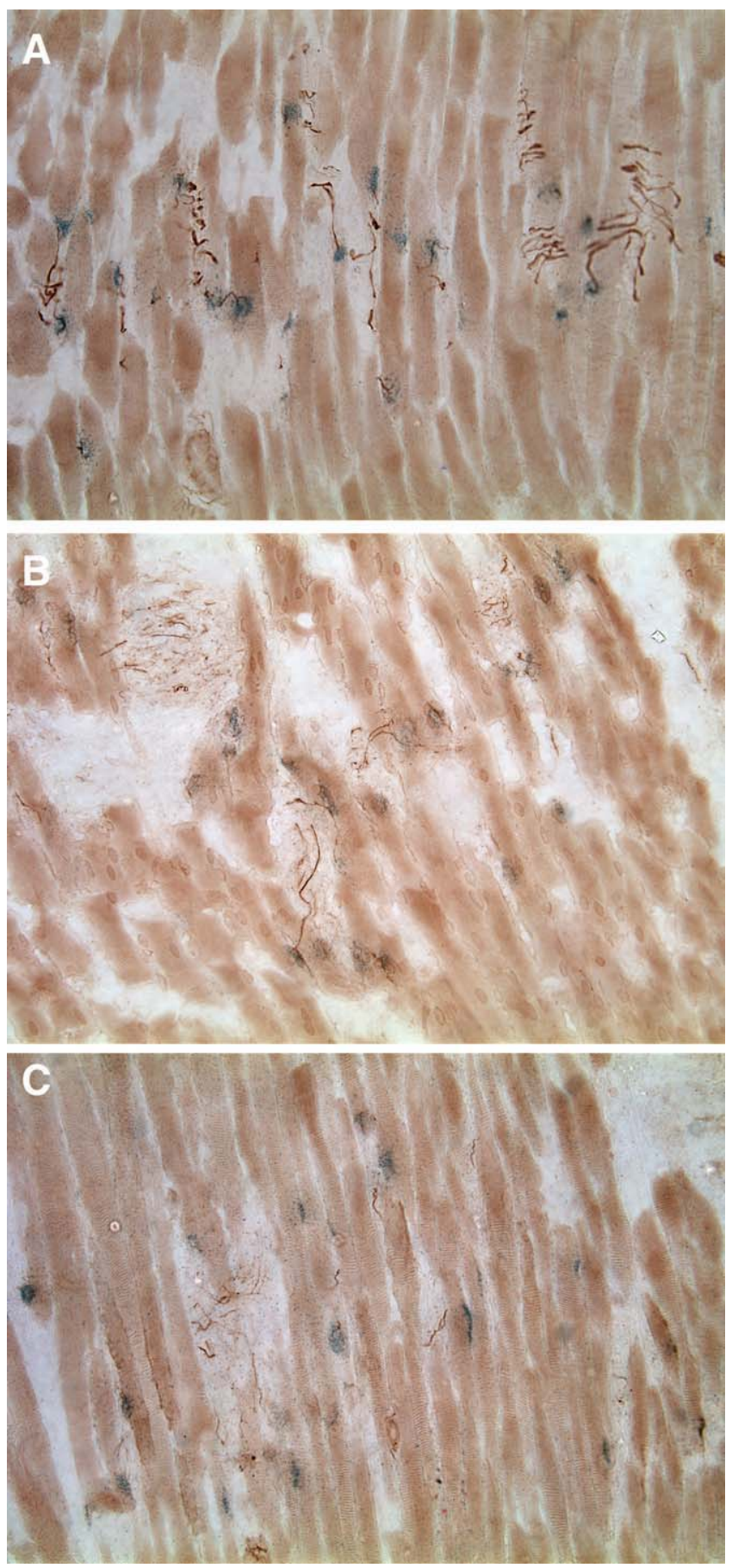

Fig. 2. Nerve endplate contact (20x). (A) Thyroarytenoid muscle on uncrushed side after acetylcholinesterase and neurofilament immunohistochemistry. Blue are endplates, brown is neurofilament. High percentage of endplates are touched by neurofilament. (B) Thyroarytenoid muscle 1 week after recurrent laryngeal nerve (RLN) crush in a group treated with AAV2-TO-6876vp16 (insulinlike growth factor-I activator gene). Approximately half of motor endplates are contacted by neurofilament. (C) Thyroarytenoid muscle 1 week after RLN crush in group treated with AAV2CMVeGFP (no activator gene). Fewer than half of the motor endplates are contacted by neurofilament.

regeneration from nerves that fire in a coordinated fashion during adduction or abduction. Muscle-nerve-muscle neurotization is a promising technique in which a graft 
is interposed between the paralyzed intrinsic laryngeal muscle and a contralateral muscle with the same function (e.g., adductor to adductor). ${ }^{47}$ The delivery of retrograde viral vectors to the donor neurons could enhance the effectiveness of regeneration and thus the success of such procedures. Restoring motion to a paralyzed vocal fold would be the ideal treatment. Ultimately, ensuring neuronal survival and enhancing nerve regeneration will be necessary to achieve this goal. Gene therapy can be useful in this pursuit.

Using the RLN to deliver factors back to the brainstem may also be useful in the treatment of bulbar involvement of neurodegenerative disorders, such as amyotrophic lateral sclerosis (ALS) ${ }^{4-6}$ Although retrograde transport might be compromised in ALS, successful retrograde delivery in the SOD1 mouse model of ALS has been reported. ${ }^{20,48}$ The ability to target specific nuclei, as well as the capability of viral vectors to move transsynaptically to other neighboring nuclei within the brainstem, offers some exciting possibilities for the use of this technique in treating bulbar ALS and other neurodegenerative diseases. Ideally, interventions can be screened initially using the crush model in normal rats, as rat models of ALS are more costly to produce and maintain.

Of course, the safety of viral gene therapy has been in question, particularly since the tragic death of an 18year-old boy with an inherited liver disease who was part of an adenoviral gene therapy protocol. The cause of death was an overwhelming immune response to the virus. ${ }^{49}$ Efforts to reduce the immunogenicity of viral vectors continue. Phase I and II clinical trials are currently going on using $\mathrm{AAV}-2$ vectors to treat diseases including cystic fibrosis, Parkinson's disease, rheumatoid arthritis, and hemophilia, among others. Some immunogenicity and toxicity have been reported. ${ }^{35}$

Other approaches to motor neuron injury or degeneration also are being explored. Embryonic stem cell research continues to hold great promise, and research efforts will likely increase so long as they are not inhibited by legal or political constraints. The potential of stem cell treatment is mired, however, by the need to control patterns of differentiation, the need for immunosuppression, and the ongoing moral debates that will likely continue. Moreover, the two approaches may not be mutually exclusive. Delivery of viral vectors may be useful to promote stem cell survival and differentiation. Viral gene therapy and stem cell therapy have the potential to work together to treat complex human diseases. $^{48}$

\section{CONCLUSION}

This study and the body of investigative work that led up to it demonstrate the potential of remote delivery of therapeutic viral vectors to the injured RLN. Rats in which AAV2-TO-6876vp16 (which carries a zinc-finger transcription factor to enhance endogenous IGF-I production) was injected remotely into the crushed RLN demonstrated greater PEC and vocal fold mobility at 1 week than rats who did not receive the therapeutic vector. The RLN offers a conduit for viral gene therapy to the brainstem, a finding that could be useful for the treatment of RLN injury or bulbar motor neuron disease. The crush model of RLN injury offers a practical approach to screen the potential therapeutic value of viral vectors.

\section{Acknowledgments}

Special thanks to S. Kaye Spratt, PhD, and Sangamo Biosciences, Inc.

\section{BIBLIOGRAPHY}

1. Federici T, Boulis N. Gene therapy for peripheral nervous system diseases. Curr Gene Ther 2007;7:239-248.

2. Rubin A, Mobley B, Hogikyan N, et al. Delivery of an adenoviral vector to the crushed recurrent laryngeal nerve. Laryngoscope 2003;113:985-989.

3. Rubin $\mathrm{AD}$, Hogikyan ND, Sullivan K, Boulis N, Feldman EL. Remote delivery of rAAV-GFP to the rat brainstem through the recurrent laryngeal nerve. Laryngoscope 2001;111:2041-2045.

4. Franz CK, Federici T, Yang J, et al. Intraspinal cord delivery of IGF-I mediated by adeno-associated virus 2 is neuroprotective in a rat model of familial ALS. Neurobiol Dis 2009;33:473-481.

5. Sakowski SA, Schuyler AD, Feldman EL. Insulin-like growth factor-I for the treatment of amyotrophic lateral sclerosis. Amyotroh Lateral Scler 2009;10:63-73.

6. Vincent AM, Sakowski SA, Schuyler A, Feldman EL. Strategic approaches to developing drug treatments for ALS. Drug Discov Today 2008;13: 67-72.

7. Boulis NM, Noordmans AJ, Song DK, et al. Adeno-associated viral vector gene expression in the adult rat spinal cord following remote vector delivery. Neurobiol Dis 2003;14:535-541.

8. Uchida K, Nakajima H, Inukai T, et al. Adenovirus-mediated retrograde transfer of neurotrophin-3 gene enhances survival of anterior horn neurons of twy/twy mice with chronic mechanical compression of the spinal cord. J Neurosci Res 2008;86:1789-1800.

9. Nakajima H, Uchida K, Kobayashi S, et al. Target muscles for retrograde gene delivery to specific spinal cord segments. Neurosci Lett 2008;435:1-6.

10. Xu K, Uchida K, Nakajima H, Kobayashi S, Baba H. Targeted retrograde transfection of adenovirus vector carrying brain-derived neurotrophic factor gene prevents loss of mouse (twy/twy) anterior horn neurons in vivo sustaining mechanical compression. Spine 2006;31:1867-1874.

11. Boulis NM, Turner DE, Dice JA, Bhatia V, Feldman EL. Characterization of adenoviral gene expression in spinal cord after remote vector delivery. Neurosurgery 1999;45:131-137; discussion 137-138.

12. Peel AL, Klein RL. Adeno-associated virus vectors: activity and applications in the CNS. J Neurosci Methods 2000;98:95-104.

13. Ronsyn MW, Berneman ZN, Van Tendeloo VF, Jorens PG, Ponsaerts P. Can cell therapy heal a spinal cord injury? Spinal Cord 2008;46: 532-539.

14. Bracken MB, Shepard MJ, Collins WF, et al. A randomized, controlled trial of methylprednisolone or naloxone in the treatment of acute spinal-cord injury. Results of the Second National Acute Spinal Cord Injury Study. N Engl J Med 1990;322:1405-1411.

15. Engstrom M, Berg T, Stjernquist-Desatnik A, et al. Prednisolone and valaciclovir in Bell's palsy: a randomised, double-blind, placebo-controlled, multicentre trial. Lancet Neurol 2008;7:993-1000.

16. Shemirani NL, Schmidt M, Friedland DR. Sudden sensorineural hearing loss: an evaluation of treatment and management approaches by referring physicians. Otolaryngol Head Neck Surg 2009;140:86-91.

17. Turk-Boru U, Kocer A, Bilge C. The efficacy of steroids in idiopathic facial nerve paralysis: an open, randomized, prospective controlled study. $K u$ lak Burun Bogaz Ihtis Derg 2005;14:62-66.

18. Finger RP, Gostian AO. Idiopathic sudden hearing loss: contradictory clinical evidence, placebo effects and high spontaneous recovery rate-where do we stand in assessing treatment outcomes? Acta Otolaryngol 2006; 126:1124-1127.

19. Lepore AC, Haenggeli C, Gasmi M, et al. Intraparenchymal spinal cord delivery of adeno-associated virus IGF-1 is protective in the SOD1G93A model of ALS. Brain Res 2007;1185:256-265.

20. Kaspar BK, Llado J, Sherkat N, Rothstein JD, Gage FH. Retrograde viral delivery of IGF-1 prolongs survival in a mouse ALS model. Science 2003;301:839-842.

21. Leinninger GM, Feldman EL. Insulin-like growth factors in the treatment of neurological disease. Endocr Dev 2005;9:135-159.

22. Sullivan KA, Kim B, Feldman EL. Insulin-like growth factors in the peripheral nervous system. Endocrinology 2008;149:5963-5971.

23. Kwon BK, Liu J, Lam C, et al. Brain-derived neurotrophic factor gene transfer with adeno-associated viral and lentiviral vectors prevents rubrospinal neuronal atrophy and stimulates regeneration-associated gene expression after acute cervical spinal cord injury. Spine 2007;32:1164-1173.

24. Houweling DA, Lankhorst AJ, Gispen WH, Bar PR, Joosten EA. Collagen containing neurotrophin-3 (NT-3) attracts regrowing injured 
corticospinal axons in the adult rat spinal cord and promotes partial functional recovery. Exp Neurol 1998;153:49-59.

25. Bloch J, Fine EG, Bouche N, Zurn AD, Aebischer P. Nerve growth factorand neurotrophin-3-releasing guidance channels promote regeneration of the transected rat dorsal root. Exp Neurol 2001;172:425-432.

26. Kirik D, Rosenblad C, Bjorklund A, Mandel RJ. Long-term rAAV-mediated gene transfer of GDNF in the rat Parkinson's model: intrastriatal but not intranigral transduction promotes functional regeneration in the lesioned nigrostriatal system. J Neurosci 2000;20:4686-4700.

27. Sondell M, Sundler F, Kanje M. Vascular endothelial growth factor is a neurotrophic factor which stimulates axonal outgrowth through the flk1 receptor. Eur J Neurosci 2000;12:4243-4254.

28. Skold MK, Kanje M. Vascular endothelial growth factor in central nervous system injuries - a vascular growth factor getting nervous? Curr Neurovasc Res 2008;5:246-259.

29. Vergani L, Di Giulio AM, Losa M, Rossoni G, Muller EE, Gorio A. Systemic administration of insulin-like growth factor decreases motor neuron cell death and promotes muscle reinnervation. $J$ Neurosci Res 1998 ; 54:840-847.

30. Contreras PC, Steffler C, Yu E, Callison K, Stong D, Vaught JL. Systemic administration of rhIGF-I enhanced regeneration after sciatic nerve crush in mice. J Pharmacol Exp Ther 1995;274:1443-1449.

31. Cheng HL, Randolph A, Yee D, Delafontaine P, Tennekoon G, Feldman EL. Characterization of insulin-like growth factor-I and its receptor and binding proteins in transected nerves and cultured Schwann cells. $J$ Neurochem 1996;66:525-536.

32. Pu SF, Zhuang HX, Ishii DN. Differential spatio-temporal expression of the insulin-like growth factor genes in regenerating sciatic nerve. Brain Res Mol Brain Res 1995;34:18-28.

33. Wuarin L, Guertin DM, Ishii DN. Early reduction in insulin-like growth factor gene expression in diabetic nerve. Exp Neurol 1994;130:106-114.

34. Shiotani A, O'Malley BW Jr, Coleman ME, Flint PW. Human insulinlike growth factor 1 gene transfer into paralyzed rat larynx: single vs multiple injection. Arch Otolaryngol Head Neck Surg 1999;125:555-560.

35. Daya S, Berns KI. Gene therapy using adeno-associated virus vectors. Clin Microbiol Rev 2008;21:583-593.

36. Jamieson AC, Miller JC, Pabo CO. Drug discovery with engineered zincfinger proteins. Nat Rev Drug Discov 2003;2:361-368.
37. Reik A, Zhou Y, Collingwood TN, et al. Enhanced protein production by engineered zinc finger proteins. Biotechnol Bioeng 2007;97:1180- 1189 .

38. Snowden A, Zhang L, Urnov $\mathrm{F}$, et al. Repression of vascular endothelial growth factor A in glioblastoma cells using engineered zinc finger transcription factors. Cancer Research 2003;63:8968- 8976.

39. Zhang L, Spratt SK, Liu Q, et al. Synthetic zinc finger transcription factor action at an endogenous chromosomal site. Activation of the human erythropoietin gene. J Biol Chem 2000;275:33850-33860.

40. Liu PQ, Rebar EJ, Zhang L, et al. Regulation of an endogenous locus using a panel of designed zinc finger proteins targeted to accessible chromatin regions. Activation of vascular endothelial growth factor A. $J$ Biol Chem 2001;276:11323-11334.

41. Klug A. The discovery of zinc fingers and their development for practical applications in gene regulation and genome manipulation. $Q$ Rev Biophys 2010;43:1-21.

42. Klug A. The discovery of zinc fingers and their applications in gene regulation and genome manipulation. Annu Rev Biochem 2010;79: 213-231.

43. Turner DE, Noordmans AJ, Feldman EL, Boulis NM. Remote adenoviral gene delivery to the spinal cord: contralateral delivery and reinjection. Neurosurgery 2001;48:1309-1316; discussion, 1309-1316.

44. Federici T,Liu JK, Teng Q, Yang J, Boulis NM. A means for targeting therapeutics to peripheral nervous system neurons with axonal damage. Neurosurgery 2007;60:911-918; discussion, 911-918.

45. Pestronk A, Drachman DB. A new stain for quantitative measurement of sprouting at neuromuscular junctions. Muscle Nerve 1978;1:70-74.

46. Fung K, Hogikyan ND, Heavner SB, Ekbom D, Feldman EL. Development and characterisation of an experimental recurrent laryngeal nerve injury model for the study of viral gene therapy. J Laryngol Otol 2008; 122:500-505.

47. Hogikyan ND, Johns MM, Kileny PR, Urbanchek M, Carroll WR, Kuzon WM Jr. Motion-specific laryngeal reinnervation using muscle-nervemuscle neurotization. Ann Otol Rhinol Laryngol 2001;110:801-810.

48. Tanase D, Teng Q, Krishnaney AA, Liu JK, Garrity-Moses ME, Boulis NM. Cervical spinal cord delivery of a rabies G protein pseudotyped lentiviral vector in the SOD-1 transgenic mouse. J Neurosurg Spine 2004 1:128-136.

48. Beardsley T. Gene therapy setback. Sci Am 2000;282:36-37. 